\title{
Gaya kepemimpinan transformasional kepala sekolah terhadap kinerja guru
}

\author{
(Principal transformational leadership style to teacher \\ performance)
}

\author{
Luthfi Akbar', Nani Imaniyati ${ }^{*}$ \\ ${ }^{1,2}$ Program Studi Pendidikan Manajemen Perkantoran, \\ Fakultas Pendidikan Ekonomi dan Bisnis, Universitas Pendidikan Indonesia \\ JI. Dr. Setiabudhi, No. 229 Bandung, Jawa Barat Indonesia \\ Email: naniimaniyati@upi.edu
}

\begin{abstract}
ABSTRAK
Permasalahan yang dikaji dalam penelitian ini adalah belum optimalnya kinerja guru di SMK Bina Warga Kota Bandung. Hal tersebut ditandai dengan pencapaian kinerja guru dalam realisasinya belum sesuai dengan target yang direncanakan yang disebabkan oleh belum optimalnya kepemimpinan kepala sekolah. Penelitian ini terdiri dari dua variabel yaitu gaya kepemimpinan transformasional kepala sekolah (X) dan kinerja guru (Y). Tujuan dari penelitian ini adalah untuk memperoleh gambaran mengenai adanya gaya kepemimpinan transformasional kepala sekolah, memperoleh gambaran mengenai adanya tingkat kinerja guru, dan untuk mengetahui apakah ada pengaruh dari gaya kepemimpinan transformasional kepala sekolah terhadap kinerja guru. Metode yang digunakan dalam penelitian ini adalah metode eksplanatory survey. Teknik pengumpulan data dengan cara penyebaran angket dengan model skala likert, yang dianalisis menggunakan regresi sederhana. Populasinya yaitu 52 orang guru di SMK Bina Warga Kota Bandung. Teknik analisis data yang digunakan adalah uji regresi linier sederhana. Berdasarkan hasil penelitian, didapatkan informasi bahwa gaya kepemimpinan transformasional kepala sekolah berada pada kategori efektif dan kinerja guru berada pada kategori sedang. Selanjutnya, data yang diperoleh berpola linier. Dari hasil uji hipotesis diperoleh bahwa gaya kepemimpinan transformasional kepala sekolah berpengaruh positif terhadap kinerja guru di SMK Bina Warga Kota Bandung.
\end{abstract}

Kata Kunci: Gaya Kepemimpinan Transformasional Kepala Sekolah; Kinerja Guru

\begin{abstract}
The problem studied in this research is not yet optimal performance of teachers in SMK Bina Warga Kota Bandung. It is marked by the achievement of teacher performance in its realization not yet in accordance with the planned target which
\end{abstract}

Received: Februari 2019, Revision: Mei 2019, Published: Juli 2019 
is caused by not optimal of headmaster leadership. This study consists of two variables: the principal transformational leadership style $(X)$ and teacher performance $(Y)$. The purpose of this study is to obtain a description of the transformational leadership style of the principal, to get an idea of the teacher's level of performance, and to see if there is any effect of the headmaster's transformational leadership style on teacher performance. The method used in this research is eksplanatory survey method. Technique of collecting data by way of dispersion of questionnaire with likert scale model, which is analyzed using simple regression. Its population is 52 teachers in SMK Bina Warga Kota Bandung. Data analysis technique used is simple linear regression test. Based on the results of the research, it is found that the headmaster's transformational leadership style is in the effective category and the teacher's performance is in the medium category. Furthermore, the data obtained is linear patterned. From the result of hypothesis test, it is found that the transformational leadership style of principal has a positive effect on teacher performance in SMK Bina Warga Kota Bandung.

Keywords: Principal Transformational Leadership Style; Teacher Performance

\section{PENDAHULUAN}

Salah satu upaya yang dilakukan pemerintah untuk menciptakan sumber daya manusia yang berkualitas ialah melalui pendidikan. Sejalan dengan Undang-undang No 20 Tahun 2003 tentang pendidikan, bahwa pendidikan adalah usaha sadar dan terencana untuk mewujudkan suasana belajar dan proses pembelajaran agar peserta didik secara aktif mengembangkan potensi dirinya untuk memiliki kekuatan spiritual keagamaan, pengembangan diri, kepribadian, kecerdasan, akhlak mulia, serta keterampilan yang diperlukan dirinya, masyarakat, bangsa dan negara.

Namun seiring dengan adanya perkembangan teknologi, informasi dan komunikasi yang pesat sehingga memberikan pengaruh pula pada dunia pendidikan. Saat ini para tenaga pendidik memiliki tuntutan kerja yang lebih kompleks. Oleh karena itu, setiap lembaga pendidikan harus mampu meningkatkan kualitas dan mutu pendidikan salah satunya dengan cara peningkatan kinerja guru dalam mengajar.

Menurut Uno, H.B. dan Lamatenggo, (2012) menyatakan bahwa "Kinerja guru adalah perilaku seseorang yang membuahkan hasil kerja tertentu setelah memenuhi sejumlah persyaratan".

Fenomena mengenai belum optimalnya kinerja guru pada salah satu SMK swasta di Kota Bandung mejadi isu yang menarik untuk dikaji. Dilihat dari kinerja yang masih jauh dari standar penilaiain yang diharapkan yaitu 100\%. Pertanyaan yang muncul mengapa kinerja guru belum optimal ? Untuk itu perlu dicari faktor-faktor yang diduga berpengaruh terhadap kinerja guru yang belum optimal.

Adapun tinggi atau rendahnya kinerja guru dapat disebabkan oleh berbagai faktor, baik faktor internal maupun faktor eksternal. Faktor eksternal yang dapat mempengaruhi kinerja para guru diantaranya ialah gaya kepemimpinan yang digunakan oleh kepala sekolah tersebut. Hal ini dikarenakan seorang pemimpin bertugas untuk menggerakkan bawahannya dalam upaya meningkatkan kinerja para bawahannya agar lebih baik dan mengalami peningkatan. Hal ini sejalan dengan pendapat dari Amstrong dan Baron (dalam Wibowo, 2007) bahwa faktor-faktor yang mempengaruhi kinerja guru adalah personal factor, leadership factor, team factor, system factor, contextual/situasional factor. 
Seorang Kepala Sekolah merupakan tokoh yang memiliki peran dalam mengendalikan kegiatan sekolah untuk mencapai berbagai tujuan pendidikan, termasuk didalamnya dalam memberdayakan sumber daya yang ada. Kinerja merupakan salah satu ukuran baik secara kualitatif maupun kuantitatif dari hasil kerja guru, oleh karena itu kinerja guru harus menjadi suatu hal yang diperhatikan oleh seorang kepala sekolah. Menurut Bruce dan Kathleen (2006) mengemukakan bahwa "Seorang pemimpin adalah satu atau lebih orang yang memilih, melengkapi, melatih, dan mempengaruhi satu atau lebih pengikut yang memiliki beragam penghargaan, kemampuan, dan keterampilan dan berfokus pengikut untuk misi organisasi dan tujuan menyebabkan pengikut rela dan antusias mengeluarkan energi spiritual, emosional dan fisik dalam upaya yang terkoordinasi bersama untuk mencapai misi dan tujuan organisasi."

Berdasarkan hal tersebut, secara khusus penelitian ini mempertanyakan adakah pengaruh gaya kepemimpinan transformasional kepala sekolah terhadap kinerja guru. Dengan demikian tujuan dari penelitian ini adalah untuk menganalisis seberapa besar pengaruh gaya kepemipinan transformasional kepala sekolah terhadap kinerja guru.

\section{KAJIAN PUSTAKA}

\section{Gaya Kepemimpinan Transformasional}

Dalam perkembangannya, studi tentang kepemimpinan berkembang sejalan dengan kemajuan zaman salah satunya gaya kepemimpinan transformasional. Kepemimpinan transformasional dibangun dari dua kata, yaitu kepemimpinan (leadership) dan transformasional (transformational). Kepemimpinan merupakan setiap tindakan yang dilakukan oleh seseorang untuk mengkoordinasikan, mengarahkan, dan mempengaruhi orang lain dalam memilih dan mencapai tujuan yang telah ditetapkan. Sedangkan istilah transformasi berasal dari kata "to transform", yang bermakna mentransformasikan atau mengubah sesuatu menjadi bentuk lain yang berbeda, misalnya mentransformasikan visi menjadi realita, atau mengubah sesuatu yang potensial menjadi aktual. Konsep awal tentang kepemimpinan transformasional ini dikemukakan oleh Burns dalam Sovya (2005) yang menjelaskan bahwa kepemimpinan transformasional adalah suatu proses dimana pimpinan dan para bawahannya untuk mencapai tingkat moralitas dan motivasi yang lebih tinggi.

Gaya kepemimpinan transformasional akan mampu membawa kesadaran pengikutnya dengan memunculkan ide-ide produktif, hubungan yang sinergikal, dan mewujudkan tujuan dari organisasi yang telah ditetapkan. Menurut James Mac Gregor Burns dalam Sri Rahmi (2014) Kepemimpinan transformasional merupakan gaya kepemimpinan dimana pimpinan dan para bawahannya berusaha untuk mencapai tingkat moralitas dan motivasi yang lebih tinggi. Parameter yang digunakan unntuk mengukur gaya kepemimpinan ini adalah dengan melihat dari tingkat kepercayaan, kepatuhan, kekaguman, kesetiaan dan rasa hormat para pengikutnya. Paramater ini digunakan dengan alasan bahwa pengikut pemimpin transformasional akan termotivasi untuk terus melakukan hal yang lebih baik lagi untuk mencapai sasaran organisasi.

Menurut House, dkk 1996 dalam Tatty dan Dedy (2010) dijelaskan bahwa pimpinan transformasional merupakan pemimpin pembaharuan yang dapat membantu menciptakan suatu lingkungan kebanggaan, loyalitas, bukan ketakutan dan intimidasi. Pemimpin pembaharuan memiliki peran strategis sebagai berikut : (1) Memperbaiki penampilan sumberdaya manusia dan sumber daya lainnya, serta untuk memperbaiki 
kualitas, meningkatkan hasil, dan secara simultan untuk menimbulkan kebanggan semangat kerja para bawahannya, (2) Tidak hanya menemukan dan mencatat kegagalan dari sumber daya manusia, melainkan untuk menghasilkan sebab-sebab kegagalan, membantu bawahan untuk melakukan tugas yang lebih baik, (3) Menciptakan suatu lingkungan kerja yang produktif, menampilkan kepemimpinan yang inovatif, dan melatih para bawahan demi melaksanakan tugas.

Engkoswara dan Aan (2011) menguraikan bahwa pemimpin transformasional adalah pemimpin yang memiliki wawasan jauh ke depan dan berupaya memperbaiki dan mengembangkan organisasi bukan untuk saat ini tapi di masa yang akan datang. Oleh karena itu, pemimpin transformasional adalah pemimpin yang dapat dikatakan sebagai pemimpin visioner.

\section{Kinerja Guru}

Menurut Cherington (dalam Khaerul Umam, 2010) bahwa: "Kinerja menunjukan pencapaian target kerja yang berkaitan dengan kualitas, kuantitas, dan waktu. Pencapaian kinerja tersebut dipengaruhi oleh kecakapan dan waktu. Kinerja yang optimal akan terwujud bilamana organisasi dapat memilih karyawan yang memiliki motivasi dan kecakapan yang sesuai dengan pekerjaannya serta memiliki kondisi yang memungkinkan mereka agar bekerja secara maksimal."

Stephen P. Robbins (2003) menyatakan bahwa: "Performance is an effort of individuals who direct them to remuneration which they value, based on their potential". (kinerja merupakan upaya individu yang mengarahkan mereka terhadap balas jasa yang mereka hargai, berdasarkan atas potensi yang mereka miliki.)

Menurut John Bernardin (2003) bahwa: "Performance is defined as the record of outcomes produced on specified job functions or activities during a specified time periode". (Kinerja adalah hasil dari prestasi kerja yang telah dicapai seorang karyawan sesuai dengan fungsi tugasnya pada periode tertentu.)

Menurut Luthans (2005) dalam pendekatan perilaku manajemen, kinerja adalah kuantitas atau kualitas suatu yang dihasilkan atau jasa yang diberikan oleh seseorang yang melakukan pekerjaan.

Guru sebagai pengemban tugas dan peranan yang sentral dalam proses pembelajaran sangat perlu untuk memberikan kinerja yang baik sebagai perwujudan dan pelaksanaan tugas profesionalnya. Sebab kinerja guru nantinya akan mempengaruhi hasil yang diperoleh siswa selama pembelajaran. Uno, H.B. dan Lamatenggo (2012) menyatakan bahwa: Kinerja guru adalah perilaku seseorang yang membuahkan hasil kerja tertentu setelah memenuhi sejumlah persyaratan.

Amstrong dan Baron (dalam Wibowo, 2007) menyatakan bahwa faktor-faktor yang mempengaruhi kinerja guru, yaitu : (1) Personal factor: ditunjukan oleh tingkat keterampilan, kompetensi yang dimiliki, motivasi dan komitmen individu, (2) Leadership factor: ditentukan oleh kualitas dorongan, bimbingan dan dukungan yang dilakukan manajer dan team leader, (3) Team factor: ditunjukan oleh kualitas dukungan yang diberikan oleh rekan sekerja, (4) System factor: ditunjukan oleh adanya sistem kerja dan fasilitas yang diberikan organisasi, (5) Contextual/situasional factor: ditunjukan oleh tingginya tingkat tekanan dan perubahan lingkungan internal dan eksternal. 
Menurut Mithcell dalam Mulyasa (2007) aspek-aspek yang dapat dijadikan ukuran dalam mengkaji kinerja tenaga pendidikan, antara lain: (1) Quality of work (kualitas kerja), (2) Promptness (ketepatan waktu menyelesaikan pekerjaan), (3) Intiative (prakarsa dalam menyelesaikan pekerjaan), (4) Capability (kemampuan menyelesaikan pekerjaan), (5) Comunication (kemampuan membina kerja sama dengan pihak lain).

\section{METODOLOGI}

Penelitian ini menggunakan metode Explanatory Survey. Metode ini dianggap tepat karena penelitian ini dilakukan untuk mengumpulkan informasi faktual melalui penggunaan kuesioner. Responden adalah guru di SMK Bina Warga Bandung, Provinsi Jawa Barat, Indonesia sebanyak 52 orang.

Instrumen pengumpulan data berupa angket kuisioner. Kuesioner untuk mengukur persepsi responden mengenai gaya kepemimpinan transformasional kepala sekolah yang dijabarkan dari empat indikator yaitu pengaruh idealisme, motivasi inspirasional, simulasi intelektual, pertimbangan pribadi yang terdiri atas 12 item. Dan kuesioner untuk mengukur persepsi responden mengenai kinerja guru yang dijabarkan dari lima indikator yaitu kualitas kerja, ketetapan kerja, inisiatif dalam kerja, kemampuan kerja, komunikasi yang terdiri atas 15 item.

Statistik deskriptif menggunakan skor rata-rata yang digunakan untuk memperoleh gambaran tingkat persepsi responden mengenai gaya kepemimpinan transformasional krpala sekolah dan kinerja guru. Statistik inferensial menggunakan analisis regresi ganda dan korelasi product moment yang digunakan untuk menguji hipotesis. Berdasarkan pendahuluan dan tinjauan pustaka tujuan penelitian ini untuk mengetahui pengaruh gaya kepemimpinan transformasional kepala sekolah terhadap kinerja guru maka hipotesis pada penelitian dapat dikembangkan sebagai berikut:

Hipotesis: Terdapat pengaruh gaya kepemimpinan transformasional kepala sekolah terhadap kinerja guru

\section{HASIL PENELITIAN DAN PEMBAHASAN}

\section{Gaya Kepemimpinan Transformasional Kepala Sekolah}

Skor rata-rata mencapai 3,40. Apabila disesuaikan dengan skala penafsiran pada tabel skala likert maka dikategorikan efektif. Disajikan dalam bentuk tabel sebagai berikut:

Tabel 1.

Kecenderungan Jawaban Responden Variabel Gaya Kepemimpinan Transformasional Kepala Sekolah (X)

\begin{tabular}{|l|c|c|c|}
\hline \multicolumn{1}{|c|}{ Indikator } & Item & Rata-rata & Penafsiran \\
\hline Pengaruh idealisme & $1-3$ & 3,32 & Cukup efektif \\
\hline Motivasi inspirasional & $4-6$ & 3,45 & Efektif \\
\hline Simulasi intelektual & $7-9$ & 3,46 & Efektif \\
\hline Pertimbangan pribadi & $10-12$ & 3,36 & Cukup efektif \\
\hline \multicolumn{2}{|c|}{ Rata-rata } & $\mathbf{3 , 4 0}$ & Efektif \\
\hline
\end{tabular}


Skor tertinggi variabel gaya kepemimpinan transformasional kepala sekolah berada pada simulasi intelektual. Hal ini memiliki makna bahwa kepala sekolah mampu memberikan rangsangan yang baik terhadap guru-guru, sehingga guru mampu mengerjakan setiap tugas yang diembannya dengan baik, berkat adanya simulasi intelektual yang baik dari kepala sekolah. Skor terendah adalah pengaruh idealisme. Hal ini memiliki makna bahwa kepala sekolah tidak bisa selalu memberikan perhatian pada setiap guru. Disimpulkan presepsi gaya kepemimpinan transformasional kepala sekolah di SMK Bina Warga Kota Bandung secara keseluruhan dikategorikan efektif.

\section{Kinerja Guru}

Skor rata-rata mencapai 3,37. Apabila disesuaikan dengan skala penafsiran pada tabel skala likert maka dikategorikan sedang. Disajikan dalam bentuk tabel sebagai berikut:

Tabel 2.

Kecenderungan Jawaban Responden Variabel Kinerja Guru (Y)

\begin{tabular}{|l|c|c|c|}
\hline \multicolumn{1}{|c|}{ Indikator } & Item & Rata-rata & Penafsiran \\
\hline Kualitas kerja & $1-4$ & 3,35 & Sedang \\
\hline Ketetapan kerja & $5-6$ & 3,29 & Sedang \\
\hline Inisiatif dalam kerja & $7-9$ & 3,43 & Tinggi \\
\hline Kemampuan kerja & $10-12$ & 3,41 & Tinggi \\
\hline Komunikasi Rata-rata & $13-15$ & 3,32 & Sedang \\
\hline \multicolumn{2}{|c|}{} & $\mathbf{3 , 3 7}$ & Sedang \\
\hline
\end{tabular}

Skor tertinggi kinerja guru berada pada inisiatif dalam kerja kerja. Hal ini memiliki makna bahwa guru memiliki tingkat inisiatif dalam bekerja sudah tinggi. Indikator kinerja guru terendah berada pada ketetapan kerja. Hal ini memiliki makna bahwa guru masih kurang atau belum optimal dalam melaksanakan ketetapan kerja. Disimpulkan presepsi kinerja di SMK Bina Warga Kota Bandung secara keseluruhan dikategorikan sedang.

\section{HIPOTESIS}

\section{Gaya Kepemimpinan Transformasional Kepala Sekolah sebagai Determinan Kinerja Guru}

Teknik analisis data yang digunakan untuk mengetahui pengaruh variabel gaya kepemimpinan transformasional kepala sekolah terhadap kinerja guru dengan menggunakan regresi ganda (multiple regression). Berdasarkan $\mathrm{F}_{\text {hitung }}$ yang diperoleh, nilai $F_{\text {hitung }}$ lebih besar dari nilai $\mathrm{F}_{\text {tabel }}$ atau 56,2706 > 4,0343, maka $\mathrm{H}_{0}$ ditolak dan $\mathrm{H}_{1}$ diterima maka terdapat pengaruh positif dan signifikan dari gaya kepemimpinan transformasional terhadap kinerja guru. Besarnya korelasi antara gaya kepemimpinan transformasional kepala sekolah terhadap kinerja guru sebesar 0,813. Hasil nilai perhitungan korelasi terdapat pada rentang 0,800 - 1,00 ini berarti nilai korelasi tersebut berada pada kategori sangat kuat.

Persamaan regresi ganda untuk pengaruh gaya kepemimpinan transformasional kepala sekolah terhadap kinerja guru adalah: 
$\hat{Y}=1,061+0,813(\mathrm{X})$. Tanda positif $(+)$ menunjukkan hubungan antara variabel bebas dengan variabel terikat berjalan satu arah, yang artinya setiap peningkatan atau penurunan di satu variabel, akan diikuti oleh peningkatan atau penurunan di satu variabel lainnya, sehingga apabila semakin tinggi gaya kepemimpinan transformasional kepala sekolah, maka semakin tinggi pula kinerja guru begitupun sebaliknya. Koefisien determinasi variabel gaya kepemimpinan transformasional kepala sekolah terhadap kinerja guru yang diperoleh yaitu sebesar 52,95\%, dan sisanya sebesar $47,05 \%$ dipengaruhi oleh faktor lain yang tidak diteliti dalam penelitian ini.

\section{KESIMPULAN}

Terdapat pengaruh positif dan signifikan antara gaya kepemimpinan transformasional terhadap kinerja guru. Demikian pula halnya dengan korelasi antara gaya kepemimpinan transformasional kepala sekolah terhadap kinerja guru memiliki korelasi yang sangat kuat. Dengan demikian implikasi yang dapat diambil dalam upaya meningkatkan kinerja guru yang lebih baik, perlu adanya peningkatan dari gaya kepemimpinan transformasional kepala sekolah.

\section{DAFTAR PUSTAKA}

Bernardin, H. John. (2003). Human Resources Management: An Experiential. Approach, 3rd Edition., McGraw-Hill/Irwin, New York

Bruce, Kathleen. (2006). Principles of Public Speaking. New York : Routledge

Engkoswara dan Komariah Aan. (2011). Administrasi Pendidikan. Bandung: Alfabeta

Luthans, F. (2005). Perilaku Organisasi. Yogyakarta: Andi

Mulyasa, E. (2007). Menjadi Guru Profesional Menciptakan Pembelajaran Kreatif dan Menyenangkan. Bandung: Rosdakarya

Rahmi, Sri (2014) Kepemimpinan Transformasional dan Budaya Organisasi Ilustrasi dibidang Pendidikan. Jakarta: Mitra Wacana Media

Robbins, Stephen P. 2003. Perilaku Organisasi. Diterjemahkan oleh Tim Indeks. Jakarta: Indeks Kelompok Gramedia

Tatty, dan Deddy. (2010). Kepemimpinan Pendidikan dalam Tim Dosen Administrasi Pendidikan. Pengelolaan Pendidikan. Bandung: Jurusan Administrasi Pendidikan

Umam, Khaerul. (2010). Perilaku Organisasi. Bandung: CV Pustaka Setia

Undang-Undang Republik Indonesia Nomor 20 Tahun 2003 Tentang Sistem Pendidikan Nasional

Uno, H.B \& Lamatenggo, N. (2012). Teori kinerja dan pengukurannya. Jakarta: Bumi Aksara

Wibowo, S.E. (2007). Manajemen Kinerja. Jakarta: PT RajaGrafindo Persada 